\title{
Patient Preferences for Metastatic Hormone-Sensitive Prostate Cancer Treatments: A Discrete Choice Experiment Among Men in Three European Countries
}

\author{
Hayley M. de Freitas · Tetsuro Ito · Monica Hadi · Gemma Al-Jassar • \\ Mickaël Henry-Szatkowski · Beenish Nafees · Andrew J. Lloyd
}

Received: November 23, 2018 / Published online: January 7, 2019

(C) The Author(s) 2019

\begin{abstract}
Introduction: Various treatment options are available for metastatic hormone-sensitive prostate cancer. This study aimed to quantify how men with prostate cancer in the United Kingdom (UK), Germany, and Spain perceive the risks and benefits of hypothetical abiraterone acetate plus prednisone treatment and docetaxel-based chemotherapy treatment options.
\end{abstract}

Enhanced Digital Features To view enhanced digital features for this article go to https://doi.org/10.6084/ m9.figshare.7454363.

Electronic supplementary material The online version of this article (https://doi.org/10.1007/s12325018-0861-3) contains supplementary material, which is available to authorized users.

H. M. de Freitas · M. Hadi - G. Al-Jassar Patient Centered Outcomes, Mapi, An Icon plc Company, London, UK

T. Ito $(\square)$

Health Economics and Market Access EMEA, Janssen, High Wycombe, UK

e-mail: tito6@its.jnj.com

M. Henry-Szatkowski

Patient Centered Outcomes, Mapi, An Icon plc

Company, Lyon, France

B. Nafees

Nafees Consulting Ltd, London, UK

A. J. Lloyd

Acaster Lloyd Consulting Ltd, London, UK
Methods: A targeted literature review, exploratory interviews with prostate cancer patients and oncologists, and pre-test interviews were used to develop a discrete choice experiments (DCE). The final DCE included 32 choice sets, selected using a main-effects orthogonal design, divided into two survey blocks. Paired profiles presented hypothetical treatments for prostate cancer through six attributes that could be presented at two or four levels each. Preference estimates were estimated using a conditional logit regression model. Preference results were stratified by cancer stage.

Results: A total of 152 participants (mean age 69 years) completed the DCE in the UK, Germany, and Spain. Treatment effectiveness was the main concern for the patients (difference in preference estimates between 8 and 32 months 1.443). Participants wanted to avoid pain that was not well controlled (preference dummy coding estimate -1.157 ). Participants valued a change from an oral medication to an intravenous treatment (change in preference estimate -0.416$)$ more negatively than a change from a $1 \%$ to a $5 \%$ risk of infection (change in preference estimate -0.313 ).

Conclusions: This study shows that treatment effectiveness and pain control were the most important attributes for patients with prostate cancer. These two attributes influenced more than $50 \%$ of their decision-making in this study. The risk of fatigue and mode of administration were least prioritised by patients. This 
study highlights the relative importance that Spanish, German, and British patients place on various aspects of treatment options for prostate cancer. Understanding patient preference and taking them into consideration shall help physicians when developing their treatment strategies for their patients.

Funding: Janssen.

Keywords: Abiraterone acetate; Discrete choice experiment; Preference; Prostate cancer

\section{INTRODUCTION}

Prostate cancer is the second most common cancer in men worldwide, representing $15 \%$ of the cancers diagnosed in men. The incidence rate is higher in Western and Northern Europe, which could be explained by the practice of prostate specific antigen (PSA) testing and subsequent biopsy [1]. As an example, in 2013, there were 40,372 new cases of prostate cancer (ICD-10 C61) registered in England, the equivalent of 185.7 per 100,000 population.

Patients with metastatic prostate cancer who have not previously received hormone therapy or are continuing to respond to hormone therapy (i.e. are not showing disease progression) are defined as having metastatic hormone-sensitive prostate cancer (mHSPC). 'Hormone-sensitive' may also be referred to as 'castration sensitive' in the literature. Until recently, the only standard of care for mHSPC was androgen deprivation therapy (ADT).

However, STAMPEDE [2] and CHAARTED [3] trials have demonstrated the survival benefits of treating mHSPC patients with intravenously administered docetaxel in addition to ADT $[4,5]$ and this regimen has also become the standard of care. The clinical benefits of orally administered abiraterone acetate plus prednisone in combination with ADT have also been demonstrated in both the STAMPEDE and the LATITUDE studies $[2,6]$. With several treatment options available, there is a need to identify attributes deemed important for mHSPC patients when choosing treatments and to understand patients' willingness to trade between these attributes.
Understanding the preferences of patients for different aspects of therapies can be challenging but methodologies exist which can help in this effort, including discrete choice experiments (DCE) [7-9]. DCEs involve presenting respondents with a sequence of hypothetical scenarios (choice sets) composed of two or more competing alternatives that differ among the description of several specific attributes (e.g. level of risk of experiencing a symptom, duration or occurrence of an event). Participants are asked to choose their preferred scenario [10]. Over the past two decades, DCEs have been increasingly utilised to help understand preferences in the field of health and healthcare $[11,12]$. DCEs are based on the premise that any goods or service can be described by its characteristics (or attributes) and secondly, the extent to which an individual values a good or bad service can be described in terms of the levels of these characteristics [13]. Response data are modelled within a benefit (or satisfaction) function, which provides information on whether or not the given characteristics are important; the relative importance of characteristics; and overall benefit scores for alternative scenarios [14]. In this context, a DCE should provide significant insight into the perceived burden associated with given adverse events (AEs), and their relative importance.

This study aimed to gain deeper insight into how men with various stages of prostate cancer in three European countries perceive the risks and benefits of hypothetical abiraterone acetate plus prednisone treatment and docetaxel-based chemotherapy treatment options. The study consisted of three consecutive steps which were the DCE survey development, its pre-testing, and the data collection.

\section{METHODS}

\section{Study Design}

This study conducted a DCE to measure the treatment preferences of men in three European countries with prostate cancer. The DCE study was conducted in two distinct phases: development and pre-testing of the DCE (phase 1) and 
DCE data collection via online administration of the survey (phase 2).

All procedures performed in studies involving human participants were in accordance with the ethical standards of the institutional and/or national research committee and with the 1964 Helsinki declaration and its later amendments or comparable ethical standards. The study protocol was approved by Freiburger Ethik-Kommission International (Freiburg, Germany), an independent ethics commission or review committee. Electronic informed consent was obtained from all participants before they participated in any activities related to that study.

\section{Survey Development}

Survey development took place in accordance with good research practices [15] and encompassed three activities: a targeted literature review, interviews with patients and clinical experts, and cognitive debrief interviews with patients.

A targeted literature review was conducted in Medline to identify and characterise the important issues related to health-related quality of life (HRQoL) in patients with mHSPC, as well as the AEs associated with treatments, specifically abiraterone acetate plus prednisone and docetaxel. Attributes relating to effectiveness in terms of overall survival or progressionfree survival were identified, as well as impact on HRQoL [16]. Semi-structured exploratory qualitative telephone interviews were conducted in the UK with two prostate cancer patients who had experienced both chemotherapy and abiraterone acetate plus prednisone, and two oncologists with more than 10 years of experience who were currently treating patients with prostate cancer. These interviews were conducted following studyspecific interview guides to explore further the attributes identified in the literature review, and to identify any potential additional attributes.

On the basis of both the findings from the literature review and from the exploratory qualitative interviews, six attributes were selected by the study team and included in a draft
DCE survey. To ensure that the attributes and levels selected for valuation were the most relevant, the study team considered the magnitude to which each choice set could impact the patients' quality of life. Typically, both physicians and patients indicated that fatigue was a large factor impacting quality of life when taking treatment. Physicians considered intravenous and oral modes of administration as very important factors differentiating between docetaxel and abiraterone acetate plus prednisone-based treatment options. The final attributes included were mode of administration, tiredness and fatigue, treatment benefit or effectiveness, bone pain, nausea/vomiting or diarrhoea, and risk of infection associated with treatment. For mode of administration, two levels were assigned. For tiredness and fatigue, treatment benefit or effectiveness, bone pain, nausea/vomiting or diarrhoea, and risk of infection, four levels were assigned to each attribute. The fatigue and bone pain attributes both included a visual analogue scale. Treatment effectiveness was described as a duration of time before a patient's prostate specific antigen (PSA) level rises, a typical early indication of disease progression. PSA is the standard biochemical tumour marker used to stage and assess treatment response in both localised and advanced prostate cancer [17]. In addition, on the basis of the exploratory, qualitative interviews with both physicians and patients, PSA is a marker that is well understood by patients in terms of its meaning.

The draft DCE included 32 choice sets that were defined using a fold-over orthogonal experimental design $[18,19]$ identified from a standard main effects orthogonal array that was both balanced and showed no overlap. Since 32 choice sets were expected to be too burdensome for participants to complete, the choice sets were divided into two blocks of 16 choice sets each; participants were randomised to complete one of these two blocks. The survey was translated into German and Spanish using a full forward-back translation process. An example choice set can be seen in Fig. 1 . 


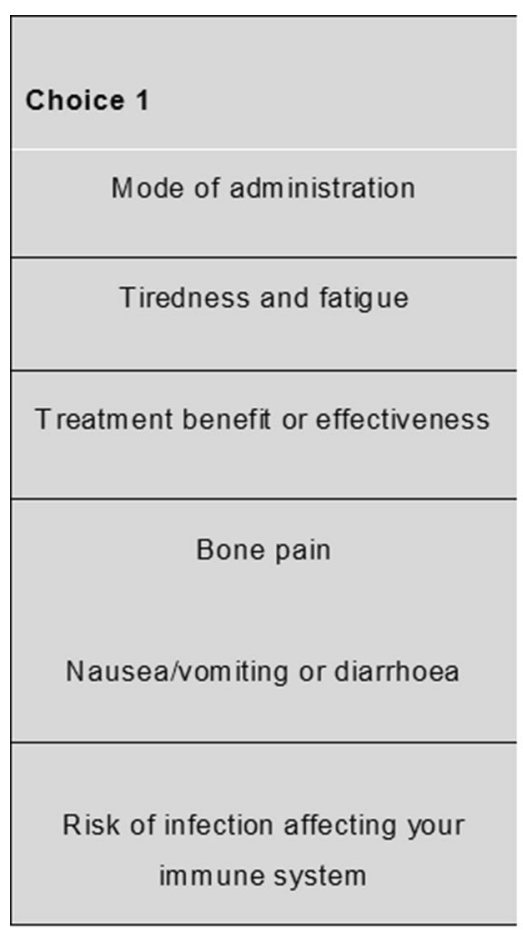

Which do you prefer?
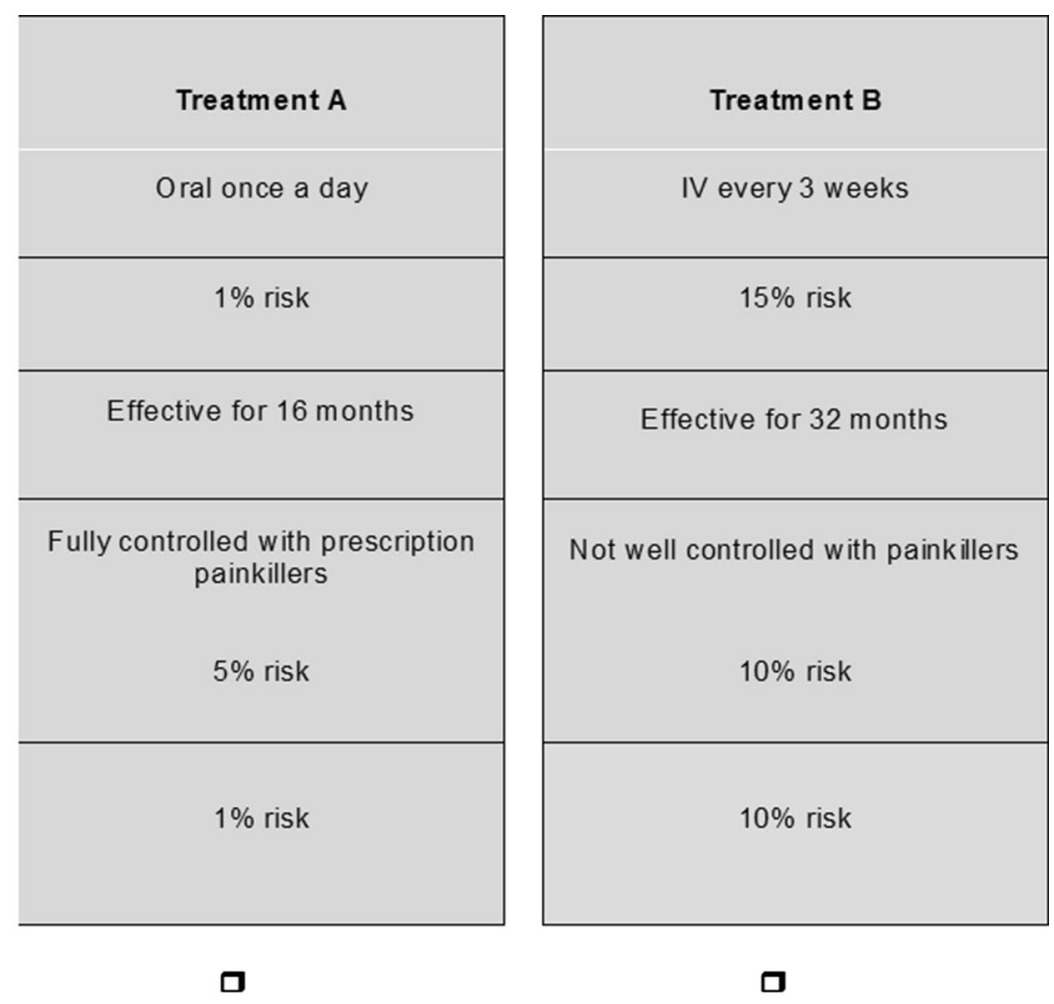

Fig. 1 Example of a choice set presented in the DCE survey

\section{Pre-testing}

Pre-test interviews were conducted to assess the comprehension and relevance of the attributes to patients of the draft DCE survey, as well as the survey instructions. The DCE survey was tested with six participants from each country recruited through a specialist recruitment agency. Participants were men diagnosed with prostate cancer currently receiving, or having received in the past, docetaxel and abiraterone acetate plus prednisone. Patients were sent a pen and paper version of the draft DCE survey prior to the interview. They were required to complete the survey including the 16 choice tasks before the date of their interview. The objective of sending the questionnaire prior to the pre-testing interview was to allow the participant to become familiar with the questionnaire and to reduce burden on these cancer patients by shortening the interview time. Prior to the start of the interview, the interviewer asked the participant whether they had completed the survey, and whether they had the survey in front of them. This facilitated the interview discussion and aided responses regarding feedback of the DCE.

Overall, participants stated that the length of the survey was adequate, that they were able to answer all the questions, and that the instructions were clear and easy to understand. Some participants provided feedback about the wording of some of the attribute levels, as well as suggestions for the layout of the survey. The feedback from the interviews in each country was used for revisions in order to produce the final version of the DCE survey. No changes to the number of choice tasks or to the experimental design were made on the basis of the pre-test interviews. Final DCE survey attributes and level descriptions are presented in Table 1.

\section{Patients}

Patients included in the DCE survey were men aged 18 years or over, with a diagnosis of prostate cancer in any of the following phases in the 
Table 1 Final DCE survey attributes and level descriptions

\begin{tabular}{|c|c|}
\hline Attributes & Levels \\
\hline \multirow[t]{2}{*}{ Mode of administration } & Oral once a day \\
\hline & Intravenous every 3 weeks \\
\hline \multirow[t]{4}{*}{ Tiredness and fatigue } & $\begin{array}{l}1 \% \text { risk of fatigue ( } 1 \text { in } 100 \\
\text { people) }\end{array}$ \\
\hline & $\begin{array}{l}5 \% \text { risk of fatigue ( } 1 \text { in } 20 \\
\text { people) }\end{array}$ \\
\hline & $\begin{array}{l}10 \% \text { risk of fatigue ( } 1 \text { in } 10 \\
\text { people) }\end{array}$ \\
\hline & $\begin{array}{l}15 \% \text { risk of fatigue (about } 1 \\
\text { in } 7 \text { people) }\end{array}$ \\
\hline \multirow[t]{4}{*}{$\begin{array}{l}\text { Treatment benefit or } \\
\text { effectiveness }\end{array}$} & $\begin{array}{l}\text { Effective for } 8 \text { months before } \\
\text { your PSA rises and you } \\
\text { need to see your physician }\end{array}$ \\
\hline & $\begin{array}{l}\text { Effective for } 16 \text { months } \\
\text { before your PSA rises and } \\
\text { you need to see your } \\
\text { physician }\end{array}$ \\
\hline & $\begin{array}{l}\text { Effective for } 24 \text { months } \\
\text { before your PSA rises and } \\
\text { you need to see your } \\
\text { physician }\end{array}$ \\
\hline & $\begin{array}{l}\text { Effective for } 32 \text { months } \\
\text { before your PSA rises and } \\
\text { you need to see your } \\
\text { physician }\end{array}$ \\
\hline \multirow[t]{4}{*}{ Bone pain } & $\begin{array}{l}\text { Fully controlled with over- } \\
\text { the-counter painkillers }\end{array}$ \\
\hline & $\begin{array}{l}\text { Fully controlled with } \\
\text { prescription painkillers }\end{array}$ \\
\hline & $\begin{array}{l}\text { Controlled with prescription } \\
\text { painkillers, most of the time }\end{array}$ \\
\hline & $\begin{array}{l}\text { Not well controlled, even } \\
\text { with prescription pain } \\
\text { killers }\end{array}$ \\
\hline
\end{tabular}

Table 1 continued

\begin{tabular}{|c|c|}
\hline Attributes & Levels \\
\hline \multirow[t]{4}{*}{$\begin{array}{l}\text { Nausea/vomiting or } \\
\text { diarrhoea }\end{array}$} & $\begin{array}{l}5 \% \text { risk of nausea/vomiting } \\
\text { or diarrhoea ( } 1 \text { in } 20 \\
\text { people) }\end{array}$ \\
\hline & $\begin{array}{l}10 \% \text { risk of nausea/vomiting } \\
\text { or diarrhoea ( } 1 \text { in } 10 \\
\text { people) }\end{array}$ \\
\hline & $\begin{array}{l}20 \% \text { risk of nausea/vomiting } \\
\text { or diarrhoea ( } 1 \text { in } 5 \text { people) }\end{array}$ \\
\hline & $\begin{array}{l}30 \% \text { risk of nausea/vomiting } \\
\text { or diarrhoea ( } 3 \text { in } 10 \\
\text { people) }\end{array}$ \\
\hline \multirow{4}{*}{$\begin{array}{l}\text { Risk of infection caused by } \\
\text { treatment affecting your } \\
\text { immune system }\end{array}$} & $\begin{array}{l}1 \% \text { risk of infection ( } 1 \text { in } 100 \\
\text { people) }\end{array}$ \\
\hline & $\begin{array}{l}5 \% \text { risk of infection ( } 1 \text { in } 20 \\
\text { people) }\end{array}$ \\
\hline & $\begin{array}{l}10 \% \text { risk of infection ( } 1 \text { in } 10 \\
\text { people) }\end{array}$ \\
\hline & $\begin{array}{l}15 \% \text { risk of infection (about } \\
1 \text { in } 7 \text { people) }\end{array}$ \\
\hline
\end{tabular}

disease pathway: biochemical recurrence (increasing blood level of PSA), locally advanced prostate cancer, or mHSPC. All participants were required to be residents of the UK, Germany, or Spain, with sufficient fluency in the local language to complete the survey. Participants with prior cytotoxic chemotherapy (such as docetaxel or cabazitaxel) or novel hormonal therapy (such as abiraterone acetate plus prednisone or enzalutamide), or presence of an acute illness or cognitive impairment that may interfere with the study requirements were excluded from the DCE survey. Participants who were unable to give informed consent or unable to complete the protocol requirements were also excluded from the DCE survey. 


\section{Survey Data Collection}

Patients who completed the final DCE survey were recruited from the UK, Germany, and Spain through a specialist recruitment agency using a variety of methods, such as newspaper advertising and word-of-mouth. Data collection took place on a website hosting the survey, which was set up specifically for the purpose of this study. Each patient included in the study was emailed the link which took them to the survey site. The first part of the survey included a screener where participants were asked some questions to determine their eligibility to take part. Eligible patients continued to the informed consent page and were required to provide their consent before proceeding. Participants were then presented a sociodemographic form collecting basic information (age, level of education, main activity, time since diagnosis, current and past treatment for prostate cancer), and then the DCE survey. Prior to completing the survey, participants were provided with an introduction and instructions, as well as detailed descriptions of each attribute and their corresponding levels (note that probabilities were presented as frequencies, percentages, and risk charts to participants). Once the screener had been completed, participants were able to move back and forth between the screens to review the instructions or attributes if needed. All participants were made aware that they could contact the study project manager if they had any questions or concerns at any point during the study. For each DCE choice set, participants were asked to choose between one of two presented profiles which described hypothetical treatments for prostate cancer through six attributes that could be presented at two or four levels each.

\section{Statistical Analysis}

The sociodemographic and clinical data were summarised in the form of frequencies and means/standard deviations (as appropriate).

A conditional logit regression model was used to assess patient preferences for various treatment attributes. In this model, the dependent variable indicates treatment choice and the independent variables represent attribute levels with one level of each attribute serving as the reference level. Attribute levels were treated as categorical variables and were analysed using dummy coding [20]. In dummy coding, coefficients represent the preference estimate of an attribute level compared to the reference level of that attribute. A preference estimate above zero indicates that participants prefer the attribute level over the reference level for that attribute, and, conversely, a preference estimate below zero indicates that participants prefer the reference level for that attribute over the specific attribute level.

A standardised relative attribute importance (RAI) score for each attribute was calculated across the subgroups to allow for between-subgroup comparisons. First, an RAI was calculated for each attribute by taking the difference between the most and least preferred level. Then, the RAI was standardised across subgroups by dividing it by the RAI of the largest RAI across the subgroups (pain among participants with a biochemical recurrence) and multiplying by 10 . The resulting number indicates the relative importance of each attribute across the subgroups (where a higher number indicates a relatively more important attribute).

It is important to note that RAI is dependent on the attribute levels included in the experiment.

Preference results were estimated for all participants on aggregate, and separately for participants in different disease stages (Biochemical Recurrence, Locally Advanced, and Metastatic) as an exploratory subgroup analysis. We did not formally test differences between the subgroups (using for example Wald tests) because of the limited sample size in each subgroup.

Analysis was performed using SAS ${ }^{\circledR}$ software for Windows Version 9.4 (SAS Institute, Inc., Cary, NC, USA).

\section{RESULTS}

\section{Patient Characteristics}

In total, 152 participants (mean age 68.9 years) completed the DCE survey (60 from the UK, 54 from Germany, and 38 from Spain). Demographics and clinical and treatment-related 
Table 2 Participant demographics

\begin{tabular}{|c|c|c|c|c|}
\hline \multirow[t]{2}{*}{ Variable } & \multicolumn{3}{|l|}{ Patient subgroups } & \multirow{2}{*}{$\begin{array}{l}\text { Total } \\
(N=152)\end{array}$} \\
\hline & $\begin{array}{l}\text { Biochemical recurrence } \\
(N=61)\end{array}$ & $\begin{array}{l}\text { Locally advanced } \\
(N=46)\end{array}$ & $\begin{array}{l}\text { Metastatic } \\
(N=45)\end{array}$ & \\
\hline \multicolumn{5}{|l|}{ Country } \\
\hline UK & $40(65.6 \%)$ & $15(32.6 \%)$ & $5(11.1 \%)$ & $60(39.5 \%)$ \\
\hline Germany & $8(13.1 \%)$ & $8(17.4 \%)$ & $38(84.4 \%)$ & $54(35.5 \%)$ \\
\hline Spain & $13(21.3 \%)$ & $23(50.0 \%)$ & $2(4.4 \%)$ & $38(25.0 \%)$ \\
\hline \multicolumn{5}{|l|}{ Age, years } \\
\hline Mean (SD) & $69.1(7.7)$ & $65.8(8.1)$ & $71.9(6.4)$ & $68.9(7.8)$ \\
\hline Min-max & $54.0-87.0$ & $45.0-79.0$ & $49.0-84.0$ & $45.0-87.0$ \\
\hline \multicolumn{5}{|l|}{ Level of education } \\
\hline $\begin{array}{l}\text { Left high school with no } \\
\text { qualifications }\end{array}$ & $6(9.8 \%)$ & $8(17.4 \%)$ & $4(8.9 \%)$ & $18(11.8 \%)$ \\
\hline Completed secondary school & $27(44.3 \%)$ & $24(52.2 \%)$ & $30(66.7 \%)$ & $81(53.3 \%)$ \\
\hline Completed some university & $14(23.0 \%)$ & $8(17.4 \%)$ & $9(20.0 \%)$ & $31(20.4 \%)$ \\
\hline Degree/postgraduate level & $14(23.0 \%)$ & $6(13.0 \%)$ & $2(4.4 \%)$ & $22(14.5 \%)$ \\
\hline \multicolumn{5}{|l|}{ Main activity } \\
\hline Employed full time & $15(24.6 \%)$ & $11(23.9 \%)$ & $4(8.9 \%)$ & $30(19.7 \%)$ \\
\hline Employed part time & $7(11.5 \%)$ & $2(4.3 \%)$ & $1(2.2 \%)$ & $10(6.6 \%)$ \\
\hline Seeking work & $0(0.0 \%)$ & $1(2.2 \%)$ & $0(0.0 \%)$ & $1(0.7 \%)$ \\
\hline Retired & $34(55.7 \%)$ & $29(63.0 \%)$ & $40(88.9 \%)$ & $103(67.8 \%)$ \\
\hline Other & $5(8.2 \%)$ & $3(6.5 \%)$ & $0(0.0 \%)$ & $8(5.3 \%)$ \\
\hline \multicolumn{5}{|l|}{ Time since diagnosis (year) } \\
\hline Mean (SD) & $3.7(4.4)$ & $2.4(3.1)$ & $4.0(3.4)$ & $3.39(3.79)$ \\
\hline Min-max & $0.00-19.00$ & $0.00-16.00$ & $0.00-14.00$ & $0.00-19.00$ \\
\hline \multicolumn{5}{|l|}{ Present level of fatigue ${ }^{a}$} \\
\hline 0 (no fatigue) & $26(42.6 \%)$ & $11(23.9 \%)$ & $0(0.0 \%)$ & $37(24.3 \%)$ \\
\hline $1-5$ & $30(49.2)$ & $27(58.7 \%)$ & $36(80.0 \%)$ & $93(61.2 \%)$ \\
\hline$>5$ & $5(8.2)$ & $8(17.4 \%)$ & $9(20.0 \%)$ & $22(14.5 \%)$ \\
\hline \multicolumn{5}{|c|}{ Worst level of bone pain over the past $24 \mathrm{~h}^{\mathrm{a}}$} \\
\hline 0 (no pain) & $35(57.4 \%)$ & $20(43.5 \%)$ & $5(11.1 \%)$ & $60(39.5 \%)$ \\
\hline $1-5$ & $23(37.7 \%)$ & $23(50.0 \%)$ & $35(77.8 \%)$ & $81(53.3 \%)$ \\
\hline$>5$ & $3(4.9 \%)$ & $3(6.5 \%)$ & $5(11.1 \%)$ & $11(7.2 \%)$ \\
\hline
\end{tabular}

${ }^{a}$ As reported on a visual analogue scale ranging from 0 (no fatigue/no pain) to 10 (as bad as you can imagine) 


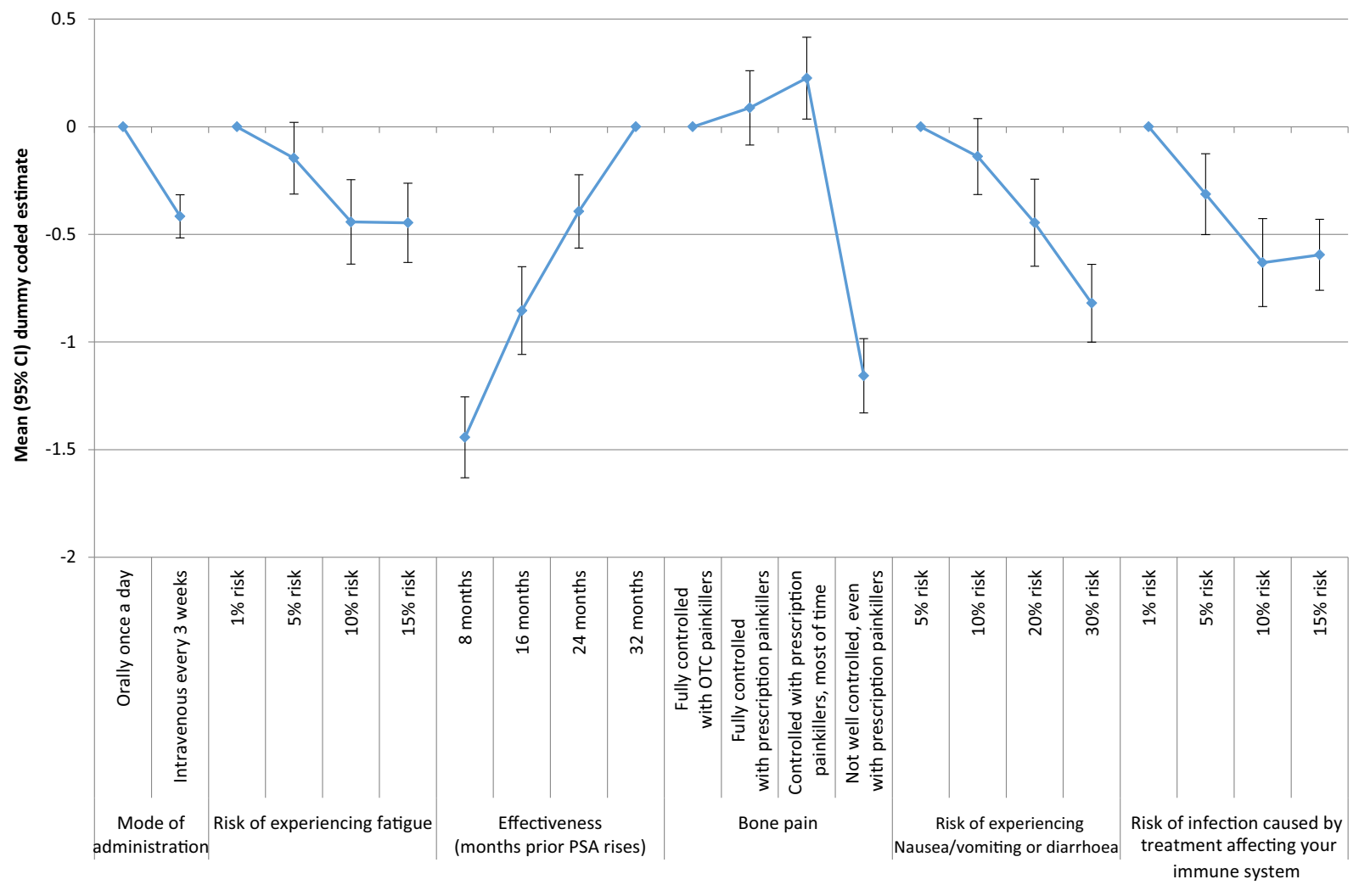

Fig. 2 Preference estimates (dummy coding) for the full population. Error bars represent $95 \%$ confidence intervals. A positive coefficient indicates that the attribute level was characteristics of the participants are presented in Table 2. Time since prostate cancer diagnosis varied, with a mean of 3.39 years (standard deviation (SD) 3.79) and ranged from 0 to 19 years. About a quarter of the participants in the total population $(n=37)$ experienced no fatigue, most of whom were patients with biochemical recurrence $(n=26)$. Almost half the total population $(n=60)$ experienced no pain, most of whom were also patients with biochemical recurrence $(n=35)$.

\section{Preference Estimates}

The results of the DCE for the full population and subgroups can be seen in Fig. 2 and in Table 3.

\section{Full Population}

Preference estimates for most attribute levels were statistically significant, indicating that more preferred than the mean preference for that attribute. A negative coefficient indicates that the attribute level was less preferred than the mean preference for that attribute

participants had significant preferences for these attribute levels compared to the reference levels. However, there was no difference in how participants viewed pain that was fully controlled with over-the-counter (OTC) painkillers or prescription painkillers $(p=0.32)$. Participants wanted to avoid pain that was not well controlled (preference estimate - 1.157) and preferred pain that was controlled with prescription painkillers most of the time (preference estimate 0.23). Generally, participants wanted to avoid lower levels of treatment effectiveness. Participants also wanted to avoid taking IV treatment every 3 weeks compared to taking medication orally once a day (preference estimate - 0.42). In the context of this DCE, participants valued a change from an oral medication to an IV more negatively than a change from a $1 \%$ risk of infection to a $5 \%$ risk of infection (change in preference estimate $-0.313)$, and almost the same as a change from a $5 \%$ to $20 \%$ risk of nausea (change in 
Table 3 Dummy coding preference estimates overall and by subgroups according to disease stage

\begin{tabular}{|c|c|c|c|c|c|c|c|c|c|}
\hline \multirow[t]{2}{*}{$\begin{array}{l}\text { Attribute } \\
\text { (reference) }\end{array}$} & \multirow[t]{2}{*}{ Attribute type } & \multicolumn{2}{|c|}{ Total $(N=152)$} & \multicolumn{2}{|c|}{$\begin{array}{l}\text { Biochemical } \\
\text { recurrence } \\
(n=61)\end{array}$} & \multicolumn{2}{|c|}{$\begin{array}{l}\text { Locally advanced } \\
(n=46)\end{array}$} & \multicolumn{2}{|c|}{$\begin{array}{l}\text { Metastatic } \\
(n=45)\end{array}$} \\
\hline & & Estimate & $p$ value & Estimate & $p$ value & Estimate & $p$ value & Estimate & $p$ value \\
\hline $\begin{array}{l}\text { Mode of } \\
\text { administration } \\
\text { (orally once a } \\
\text { day) }\end{array}$ & $\begin{array}{l}\text { Intravenous } \\
\text { every } \\
3 \text { weeks }\end{array}$ & -0.416 & $<0.001$ & -0.476 & $<0.001$ & -0.491 & $<0.001$ & -0.301 & 0.002 \\
\hline \multirow{3}{*}{$\begin{array}{l}\text { Tiredness and } \\
\text { fatigue (1\% risk } \\
\text { of experiencing } \\
\text { fatigue) }\end{array}$} & $5 \%$ risk & -0.146 & 0.086 & 0.002 & 0.986 & -0.269 & 0.073 & -0.114 & 0.480 \\
\hline & $10 \%$ risk & -0.442 & $<0.001$ & -0.458 & 0.008 & -0.360 & 0.037 & -0.507 & 0.008 \\
\hline & $15 \%$ risk & -0.446 & $<0.001$ & -0.494 & 0.002 & -0.470 & 0.004 & -0.369 & 0.044 \\
\hline \multirow{3}{*}{$\begin{array}{l}\text { Treatment benefit } \\
\text { or effectiveness } \\
\text { (effective for } \\
32 \text { months } \\
\text { before your } \\
\text { PSA rises) }\end{array}$} & $\begin{array}{l}\text { Effective for } \\
8 \text { months }\end{array}$ & -1.443 & $<0.001$ & -1.337 & $<0.001$ & -1.334 & $<0.001$ & -1.807 & $<0.001$ \\
\hline & $\begin{array}{l}\text { Effective for } \\
16 \text { months }\end{array}$ & -0.854 & $<0.001$ & -0.763 & $<0.001$ & -0.826 & $<0.001$ & -1.024 & $<0.001$ \\
\hline & $\begin{array}{l}\text { Effective for } \\
24 \text { months }\end{array}$ & -0.393 & $<0.001$ & -0.426 & 0.005 & -0.197 & 0.181 & -0.610 & $<0.001$ \\
\hline \multirow[t]{3}{*}{$\begin{array}{l}\text { Bone pain (fully } \\
\text { controlled with } \\
\text { over-the- } \\
\text { counter } \\
\text { painkillers) }\end{array}$} & $\begin{array}{l}\text { Fully } \\
\text { controlled } \\
\text { with } \\
\text { prescription } \\
\text { painkillers }\end{array}$ & 0.088 & 0.317 & 0.115 & 0.418 & 0.114 & 0.474 & 0.094 & 0.576 \\
\hline & $\begin{array}{l}\text { Controlled } \\
\text { with } \\
\text { prescription } \\
\text { painkillers, } \\
\text { most of the } \\
\text { time }\end{array}$ & 0.226 & 0.020 & 0.435 & 0.009 & -0.027 & 0.876 & 0.320 & 0.094 \\
\hline & $\begin{array}{l}\text { Not well } \\
\text { controlled, } \\
\text { even with } \\
\text { prescription } \\
\text { painkillers }\end{array}$ & -1.157 & $<0.001$ & -1.554 & $<0.001$ & -0.800 & $<0.001$ & -1.172 & $<0.001$ \\
\hline \multirow[b]{2}{*}{$\begin{array}{l}\text { Nausea/vomiting } \\
\text { or diarrhoea } \\
\text { (5\% risk of } \\
\text { nausea/ } \\
\text { vomiting or } \\
\text { diarrhea) }\end{array}$} & $10 \%$ risk & -0.138 & 0.128 & -0.225 & 0.174 & -0.012 & 0.939 & -0.249 & 0.144 \\
\hline & $\begin{array}{l}20 \% \text { risk } \\
30 \% \text { risk }\end{array}$ & $\begin{array}{l}-0.446 \\
-0.820\end{array}$ & $\begin{array}{l}<0.001 \\
<0.001\end{array}$ & $\begin{array}{l}-0.594 \\
-0.799\end{array}$ & $\begin{array}{l}<0.001 \\
<0.001\end{array}$ & $\begin{array}{l}-0.440 \\
-0.784\end{array}$ & $\begin{array}{r}0.015 \\
<0.001\end{array}$ & $\begin{array}{l}-0.380 \\
-1.078\end{array}$ & $\begin{array}{r}0.055 \\
<0.001\end{array}$ \\
\hline
\end{tabular}


Table 3 continued

\begin{tabular}{|c|c|c|c|c|c|c|c|c|c|}
\hline \multirow[t]{2}{*}{$\begin{array}{l}\text { Attribute } \\
\text { (reference) }\end{array}$} & \multirow[t]{2}{*}{ Attribute type } & \multicolumn{2}{|c|}{ Total $(N=152)$} & \multicolumn{2}{|c|}{$\begin{array}{l}\text { Biochemical } \\
\text { recurrence } \\
(n=61)\end{array}$} & \multicolumn{2}{|c|}{$\begin{array}{l}\text { Locally advanced } \\
(n=46)\end{array}$} & \multicolumn{2}{|c|}{$\begin{array}{l}\text { Metastatic } \\
(n=45)\end{array}$} \\
\hline & & Estimate & $p$ value & Estimate & $p$ value & Estimate & $p$ value & Estimate & $p$ value \\
\hline \multirow{3}{*}{$\begin{array}{l}\text { Risk of infection } \\
\text { affecting your } \\
\text { immune system } \\
\text { (1\% risk of } \\
\text { infection) }\end{array}$} & $\begin{array}{l}5 \% \text { risk of } \\
\text { infection }\end{array}$ & -0.313 & 0.001 & -0.403 & 0.015 & -0.364 & 0.025 & -0.223 & 0.224 \\
\hline & $\begin{array}{c}10 \% \text { risk of } \\
\text { infection }\end{array}$ & -0.631 & $<0.001$ & -0.939 & $<0.001$ & -0.696 & $<0.001$ & -0.203 & 0.303 \\
\hline & $\begin{array}{c}15 \% \text { risk of } \\
\text { infection }\end{array}$ & -0.595 & $<0.001$ & -0.888 & $<0.001$ & -0.536 & $<0.001$ & -0.387 & 0.013 \\
\hline
\end{tabular}

A positive coefficient indicates that the attribute level was more preferred than the reference level. A negative coefficient indicates that the attribute level was less preferred than the reference level

Table 4 Relative attribute importance

\begin{tabular}{|c|c|c|c|c|c|c|c|c|}
\hline \multirow[t]{2}{*}{ Attribute } & \multicolumn{2}{|l|}{ Total } & \multicolumn{2}{|c|}{$\begin{array}{l}\text { Biochemical recurrence } \\
(n=61)\end{array}$} & \multicolumn{2}{|c|}{$\begin{array}{l}\text { Locally advanced } \\
(n=46)\end{array}$} & \multicolumn{2}{|c|}{$\begin{array}{l}\text { Metastatic } \\
(n=45)\end{array}$} \\
\hline & $\overline{\mathrm{RAI}^{\mathrm{a}}}$ & $\overline{\text { Rank }}$ & $\overline{\mathrm{RAI}^{\mathrm{a}}}$ & Rank & $\overline{\mathbf{R A I}^{\mathbf{a}}}$ & Rank & $\overline{\mathbf{R A I}^{\mathbf{a}}}$ & Rank \\
\hline Mode of administration & 2.09 & 6 & 2.39 & 6 & 2.47 & 5 & 1.51 & 6 \\
\hline Fatigue & 2.24 & 5 & 2.49 & 5 & 2.36 & 6 & 2.55 & 4 \\
\hline Effectiveness & 7.25 & 1 & 6.72 & 2 & 6.71 & 1 & 9.08 & 1 \\
\hline Pain control & 6.26 & 2 & 10.00 & 1 & 4.60 & 2 & 6.37 & 2 \\
\hline Nausea/vomiting & 4.12 & 3 & 4.02 & 4 & 3.94 & 3 & 5.42 & 3 \\
\hline Infection & 3.17 & 4 & 4.31 & 3 & 5.59 & 4 & 3.11 & 5 \\
\hline
\end{tabular}

a A standardised RAI for each attribute was calculated across the subgroups to allow for across-subgroup comparisons. First, an RAI was calculated for each attribute by taking the difference between the most and least preferred level. Then, the RAI was standardised across subgroups by dividing it by the RAI of the most important attribute across the subgroups (pain among participants with a biochemical recurrence) and multiplying by 10 . The resulting number indicates the relative importance of each attribute across the subgroups (where a higher number indicates a relatively more important attribute)

preference estimate -0.446$)$ and a change from $1 \%$ to $15 \%$ risk of fatigue (change in preference estimate - 0.446).

In the overall sample treatment effectiveness was the main concern for the participants (RAI 7.25) and pain control was the second most important attribute (RAI 6.26) (Table 4). Risk of nausea and nausea/vomiting were the third and fourth most important (RAI 4.12 and 3.17, respectively). Finally risk of fatigue and mode of administration were the fifth and sixth most important (RAI 2.24 and 2.09, respectively).
DCE results are heavily dependent on the attribute levels included. In this study the risk levels varied considerably between the different risk attributes. For example, the RAI for the risk of vomiting in the full sample was 4.12 while the RAI for the risk of fatigue was only 2.24. However, the risk levels for vomiting spanned a $25 \%$ risk difference (from 30\% to 5\%) while the risk levels for fatigue only spanned 14\% (from $1 \%$ to $15 \%$ ). However, when more similar changes in risk level were compared, the preference estimate for a change from $1 \%$ to $15 \%$ 
fatigue $(0.446)$ is very similar to the preference estimate for a change from $5 \%$ to $20 \%$ risk of nausea (0.446). Therefore, it Is important to consider the attribute levels included when making inferences about preference results.

\section{Exploratory Subgroup Analysis}

Participants with biochemical recurrence assigned the most importance to pain control (RAI 10.00); participants with locally advanced cancer and with metastatic cancer assigned the most importance to effectiveness (RAI 6.71 and 9.08, respectively). Participants with biochemical recurrence assigned the least importance to mode of administration (RAI 2.39) and fatigue (RAI 2.49). Participants with locally advanced cancer assigned the least importance to risk of fatigue (RAI 2.36) and mode of administration (RAI 2.47). Participants with metastatic cancer assigned the least importance to mode of administration (RAI 1.51).

\section{DISCUSSION}

This study provides new insights into the relative importance that people place on aspects of treatments in prostate cancer. While mode of administration is a differentiating factor between docetaxel and abiraterone acetate plus prednisone, there are other factors including efficacy and safety which can make a difference in terms of patient preference across different treatment options. In that context, there is a need to identify attributes deemed as being important for mHSPC patients when choosing treatments, to establish treatment preference, and to understand patients' willingness to trade between these attributes. The results from this DCE can be used to inform decision-making in the healthcare environment [21], and are also useful in showing the value of these benefits to patients and therefore the aspects of treatments which healthcare professionals need to discuss with patients when they are considering which medication to take.

In our study, patients valued treatment effectiveness as the most important attribute. Our result is similar to the findings of a study by Sculpher et al. in which prostate cancer participants made trade-offs in a DCE between eight attributes, including life expectancy. The study found that the greater the life expectancy, the more likely the participant preferred that particular scenario [22]. Similarly, in a study by King et al., patients with prostate cancer were presented with scenarios which included life expectancy and seven side effects. In terms of life expectancy, participants were willing to make trade-offs between 4 and 28 more months of life expectancy depending on side effects [23].

Pain was the second most important attribute in our sample. Patients did not differentiate between full pain control that was controlled by OTC medication or by prescription medication. This might indicate that pain that is not well controlled is unacceptable to patients, but that it is harder to differentiate between less severe levels of pain. Our overall finding of patients' desire to avoid pain is consistent with the results of a study by Eliasson et al., which found that participants strongly preferred treatment that fully controlled their bone pain [24].

Consideration of patients and their treatment preferences is important when selecting treatments as highlighted by de Bekker-Grob et al. [25]. They investigated prostate cancer patients' and urologists' preference of treatment and treatment attributes and found there was a difference in preferences between the two groups. For both patients and urologists, risk of urinary incontinence was important, and active surveillance was preferred in comparison to radical treatment. However, the study found that treatment modality was an important attribute to patients, while urologists deemed the risk of erectile dysfunction important for patients. This shows that a patient and a physician may make different trade-offs when selecting the optimal treatment for the individual patient. Our study also highlights the importance of treatment attributes and their varying degrees of levels in selecting treatment.

While all three subgroups of participants according to their disease stage valued effectiveness and pain the most, the total amount of importance participants assign to both these attributes was different on the basis of their disease stage. Participants with biochemical recurrence assigned the most importance to pain control while participants with locally advanced cancer 
and with metastatic cancer assigned the most importance to effectiveness. The trend observed here shows that the more advanced the disease, the more important effectiveness is; in other words, as prognosis worsens, patients give more importance to delaying disease progression. However, care should be taken in interpreting the subgroup results because of the small sample size, and subgroup results should be interpreted as exploratory only.

\section{Study Limitations}

The recruitment of the mHSPC population who were eligible for this study was challenging, particularly in the UK and in Spain. A reason could be that such patients received novel hormonal treatment or chemotherapy as soon as their disease became metastatic. This remains a hypothesis as no information could be collected from non-responders in the absence of their consents; this is a common limitation in such surveys. The resulting imbalance in the proportion of disease stage per country in this study prevented analysis at the country level. Indeed about $84 \%$ of the German sample consisted of patients with metastatic disease, while more than half of the UK sample consisted of patients with biochemical recurrence.

Given a recent trend of larger sample sizes in the application of DCEs in health, the sample size in this study may be considered comparatively small. However, DCEs have been successfully used in the rare disease and oncology context with small sample sizes [26, 27]. Furthermore, considering that the FDA recognises that patient and healthcare professionals are preference-sensitive, in particular in the context of rare disease and oncology [28], and given known study limitations in these contexts, we believe that DCEs can be and should be conducted even when sample size cannot feasibly be large. We believe that given our study objective, a DCE was the most appropriate method to employ and have made adjustments to the study to be able to draw inference from our results, such as opting for a conditional logit rather than a mixed logit model and only conducting exploratory subgroup analyses.
As mentioned earlier in the discussion, the preference coefficient for the attribute level "pain controlled with prescription painkiller, most of the time" was higher than for pain that was fully controlled with OTC medication or with prescription medication. It is possible that participants misinterpreted these attribute levels to mean that, for fully controlled pain, they had to take medication every day, but, for pain controlled most of the time, they only had to take medication a few days per week. However, this was not something that was detected during the pre-testing interviews in any countries.

As with any DCE experiments, the results should be interpreted in light of the selected attributes and related attribute levels. One cannot exclude that other attributes not tested in this DCE could be important in the management of patients with prostate cancer. Furthermore, the relative importance of each of the attributes in this DCE was dependent on the levels included in the DCE.

\section{CONCLUSION}

Treatment effectiveness and pain control were the most important attributes for patients with prostate cancer, which influenced more than $50 \%$ of their decision-making in this study. The risk of fatigue and mode of administration were least prioritised by patients. This study highlights the relative importance that Spanish, German, and British patients place on various aspects of treatment options for prostate cancer. Understanding patient preference and taking them into consideration shall help physicians when developing their treatment strategies for their patients. Furthermore these preference data can also inform dossiers submitted to health authorities and be used to support negotiations for market access and pricing.

\section{ACKNOWLEDGEMENTS}

The authors thank patients, healthcare professionals, and members of the general public who participated in this study. 
Funding. This study was funded by Janssen. Janssen also funded the journal's article processing charges and Open Access fee. All authors had full access to all of the data in this study and take complete responsibility for the integrity of the data and accuracy of the data analysis.

Medical Writing, Editorial and Other Assistance. The authors also thank Cicely Kerr, Isabelle Girod, Lee Deavy, and Paul Swinburn for their contributions to the design and conduct of this study. The authors also thank Jérémy Lambert (Icon plc) for medical writing assistance and editorial support in the manuscript preparation funded by Janssen. The authors also thank Ellen Janssen (Icon plc) for her support in the statistical analysis.

Authorship. All named authors meet the International Committee of Medical Journal Editors (ICMJE) criteria for authorship for this manuscript, take responsibility for the integrity of the work as a whole, and have given final approval to the version to be published.

Disclosures. Hayley M de Freitas, employee of Mapi, an ICON plc company at the time the study was conducted, was a paid consultant to Janssen-Cilag Ltd. Tetsuro Ito, employee of Janssen-Cilag Ltd, a pharmaceutical company of Johnson and Johnson, has stocks of Johnson \& Johnson. Monica Hadi, employee of Mapi at the time the study was conducted, now an employee of Evidera, was a paid consultant to Janssen-Cilag Ltd. Gemma Al-Jassar, employee of Mapi, an ICON plc company, was a paid consultant to Janssen-Cilag Ltd. Mickaël HenrySzatkowski, employee of Mapi, an ICON plc company, was a paid consultant to Janssen-Cilag Ltd. Beenish Nafees, employee of Nafees Consulting Ltd, was a paid consultant to Janssen-Cilag Ltd. Andrew J Lloyd, employee of Acaster Lloyd Consulting Ltd, was a paid consultant to Janssen-Cilag Ltd.

Compliance with Ethics Guidelines. All procedures performed in studies involving human participants were in accordance with the ethical standards of the institutional and/or national research committee and with the 1964 Helsinki declaration and its later amendments or comparable ethical standards. The study protocol was approved by Freiburger EthikKommission International (Freiburg, Germany), an independent ethics commission or review committee. Electronic informed consent was obtained from all participants before they participated in any activities related to that study.

Data Availability. All data generated or analysed during this study are included in this published article.

Open Access. This article is distributed under the terms of the Creative Commons Attribution-NonCommercial 4.0 International License (http://creativecommons.org/licenses/ by-nc/4.0/), which permits any noncommercial use, distribution, and reproduction in any medium, provided you give appropriate credit to the original author(s) and the source, provide a link to the Creative Commons license, and indicate if changes were made.

\section{REFERENCES}

1. Ferlay J, Soerjomataram I, Ervik M, et al. GLOBOCAN 2012 v1.0, cancer incidence and mortality worldwide: IARC CancerBase No. 11. Lyon, France: International Agency for Research on Cancer; 2013. http://globocan.iarc.fr. Accessed 19 July 2018.

2. James ND, Sydes MR, Clarke NW, et al. Addition of docetaxel, zoledronic acid, or both to first-line longterm hormone therapy in prostate cancer (STAMPEDE): survival results from an adaptive, multiarm, multistage, platform randomised controlled trial. Lancet. 2016;387(10024):1163-77. https://doi.org/ 10.1016/S0140-6736(15)01037-5.

3. Sweeney CJ, Chen YH, Carducci M, et al. Chemohormonal therapy in metastatic hormone-sensitive prostate cancer. N Engl J Med. 2015;373(8):737-46. https://doi.org/10.1056/NEJMoa1503747.

4. Liaw BC, Oh WK. Is docetaxel chemotherapy a new standard of care for metastatic hormone-sensitive prostate cancer? Am J Hematol Oncol 2015;11(9): 17-20.

5. Shenoy N, Kohli M. Role of systemic chemotherapy in metastatic hormone-sensitive prostate cancer. 
IJU. 2016;32(4):257-61. https://doi.org/10.4103/ 0970-1591.191234.

6. Fizazi K, Tran N, Fein L, et al. Abiraterone plus prednisone in metastatic, castration-sensitive prostate cancer. N Engl J Med. 2017;377(4):352-60. https://doi.org/10.1056/NEJMoa1704174.

7. Liu FX, Witt EA, Ebbinghaus S, et al. Patient and oncologist preferences for attributes of treatments in advanced melanoma: a discrete choice experiment. Patient Prefer Adher. 2017;11:1389-99. https://doi.org/10.2147/ppa.s140226.

8. Scott A, Watson MS, Ross S. Eliciting preferences of the community for out of hours care provided by general practitioners: a stated preference discrete choice experiment. Soc Sci Med. 2003;56(4): 803-14.

9. Watson V, Ryan M, Brown CT, Barnett G, Ellis BW, Emberton M. Eliciting preferences for drug treatment of lower urinary tract symptoms associated with benign prostatic hyperplasia. J Urol. 2004;172(6 Pt 1):2321-5.

10. Gerard KRM. Discrete choice experiments in a nutshell. In: Ryan M, Gerard K, Amaya-Amaya M (eds) Using discrete choice experiments to value health and healthcare. Springer, Berlin; 2008.

11. Clark MD, Determann D, Petrou S, Moro D, de Bekker-Grob EW. Discrete choice experiments in health economics: a review of the literature. Pharmacoeconomics. 2014;32(9):883-902. https://doi. org/10.1007/s40273-014-0170-X.

12. de Bekker-Grob EW, Ryan M, Gerard K. Discrete choice experiments in health economics: a review of the literature. Health Econ. 2012;21(2):145-72. https://doi.org/10.1002/hec.1697.

13. Ryan M, Bate A, Eastmond CJ, Ludbrook A. Use of discrete choice experiments to elicit preferences. Qual Health Care. 2001;10(Suppl 1):i55-60.

14. Louviere JSB. Stated preference methods. Handbook of transport modeling. 1st ed. Oxford: Elsevier; 2000.

15. Bridges JF, Hauber AB, Marshall D, et al. Conjoint analysis applications in health-a checklist: a report of the ISPOR good research practices for conjoint analysis task force. Value Health. 2011;14(4): 403-13. https://doi.org/10.1016/j.jval.2010.11.013.

16. Sartor O, Flood E, Beusterien K, et al. Health-related quality of life in advanced prostate cancer and its treatments: biochemical failure and metastatic disease populations. Clin Genitourinary Cancer. 2015;13(2):101-12. https://doi.org/10.1016/j.clgc. 2014.08.001.
17. Pezaro C, Woo HH, Davis ID. Prostate cancer: measuring PSA. Internal Med J. 2014;44(5):433-40. https://doi.org/10.1111/imj.12407.

18. Janssen EM, Segal JB, Bridges JF. A framework for instrument development of a choice experiment: an application to type 2 diabetes. Patient. 2016;9(5):465-79. https://doi.org/10.1007/s40271016-0170-3.

19. Reed Johnson F, Lancsar E, Marshall D, et al. Constructing experimental designs for discrete-choice experiments: report of the ISPOR conjoint analysis experimental design good research practices task force. Value Health. 2013;16(1):3-13. https://doi. org/10.1016/j.jval.2012.08.2223.

20. Hauber AB, Gonzalez JM, Groothuis-Oudshoorn CG, et al. Statistical methods for the analysis of discrete choice experiments: a report of the ISPOR conjoint analysis good research practices task force. Value Health. 2016;19(4):300-15. https://doi.org/ 10.1016/j.jval.2016.04.004.

21. Lancsar E, Louviere J. Conducting discrete choice experiments to inform healthcare decision making: a user's guide. Pharmacoeconomics. 2008;26(8): 661-77.

22. Sculpher M, Bryan S, Fry P, de Winter P, Payne $H$, Emberton M. Patients' preferences for the management of non-metastatic prostate cancer: discrete choice experiment. BMJ. 2004;328(7436):382. https://doi.org/10.1136/bmj.37972.497234.44.

23. King MT, Viney R, Hossain I, et al. Survival gains needed to justify the side effects of treatment for localized prostate cancer. J Clin Oncol. 2009; 27(15S):5119. https://doi.org/10.1200/jco.2009.27. 15 s.5119.

24. Eliasson L, de Freitas HM, Dearden L, Calimlim B, Lloyd AJ. Patients' preferences for the treatment of metastatic castrate-resistant prostate cancer: a discrete choice experiment. Clin Ther. 2017; 39(4):723-37. https://doi.org/10.1016/j.clinthera. 2017.02.009.

25. de Bekker-Grob EW, Bliemer MCJ, Donkers B, et al. Patients' and urologists' preferences for prostate cancer treatment: a discrete choice experiment. Br J Cancer. 2013;109:633. https://doi.org/10.1038/bjc. 2013.370 .

26. Bridges JF, Mohamed AF, Finnern HW, Woehl A, Hauber AB. Patients' preferences for treatment outcomes for advanced non-small cell lung cancer: a conjoint analysis. Lung Cancer. 2012;77(1): 224-31. https://doi.org/10.1016/j.lungcan.2012.01. 016. 
27. Peay HL, Hollin I, Fischer R, Bridges JFP. A community-engaged approach to quantifying caregiver preferences for the benefits and risks of emerging therapies for Duchenne muscular dystrophy. Clin Ther. 2014;36(5):624-37. https://doi.org/10.1016/j. clinthera.2014.04.011.

28. U.S. Department of Health and Human Services Food and Drug Administration. FDA guidance-
Patient preference information-Voluntary submission, review in premarket approval applications, humanitarian device exemption applications, and de novo requests, and inclusion in decision summaries and device labeling. 2016. https://www.fda. gov/downloads/medicaldevices/deviceregulationand guidance/guidancedocuments/ucm446680.pdf. Accessed 31 Oct 2018. 